\title{
Job-related stress and work ability of dispatchers in a metropolitan fire department
}

\author{
Marcus Oldenburg ${ }^{1 * \dagger}$, Dennis Wilken ${ }^{2 \dagger}$, Ralf Wegner ${ }^{1}$, Bernd Poschadel ${ }^{1}$ and Xaver Baur ${ }^{3}$
}

\begin{abstract}
Background: Our aim was to assess psychomental stress and strain among dispatchers in fire departments, particularly during emergency instructions by phone and to evaluate their work ability.

Methods: 27 dispatchers and 20 controls were examined. In a protocol, participants recorded 1. phone instructions causing mental stress (event) 2. working time without phone instructions (non-event) 3. breaks. Continuous heart rate (variability), urine catecholamine, salivary cortisol and lymphocytes were measured. To assess the job-related burden, the Work Ability Index (WAI) was applied.

Results: Dispatchers demonstrated significantly higher heart rates and reduced standard deviation of all NN (heartbeat-to-heartbeat) intervals (SDNN) than the controls in all phases. WAl of dispatchers was significantly lower than that of the controls. Within the dispatchers, there was a significantly higher rate of inability to work during the past year.

Conclusions: The increased heart rate and reduced SDNN of examined dispatchers indicate chronic stress effects as a possible preliminary stage of a health disorder. In respect of the reduced work ability among dispatchers preventive measures are required to reduce the stress situation during their job-performance.
\end{abstract}

Keywords: Dispatchers, Emergency call, Stress and strain at the workplace, Work ability

\section{Background}

It has repeatedly been shown that emergency service personnel (such as fire fighters, policemen and dispatchers) experience more job-related stress than nonemergency workers $[1,2]$. Thus, it is assumed that this kind of stress can affect their social, psychological and emotional life [3].

The studies on fire fighters' workload mainly investigated the physical strain arising from the exposure to various noxious substances during different services with a focus on respiratory diseases $[4,5]$. But the psychological strain experienced by fire fighters also progressively moved into the focus of medical interest. Many studies deal with post-traumatic stress disorders as a result of fire-brigade operations and with the opportunities for prevention. In 1993, Boxer and Wild (1993) reported that

\footnotetext{
* Correspondence: marcus.oldenburg@bgv.hamburg.de

${ }^{\dagger}$ Equal contributors

${ }^{1}$ Institute for Occupational and Maritime Medicine, Hamburg State Department for Health and Consumer Protection, ZfAM, University Medical Center Hamburg-Eppendorf, Seewartenstrasse10, D-20459 Hamburg, Germany

Full list of author information is available at the end of the article
}

between $33 \%$ and $51 \%$ of examined fire fighters were experiencing significant psychological distress [6].

Dispatchers in mixed emergency and fire systems of fire departments are involved at the beginning of the rescue chain. They play a key role in allocating the right resource to patients in emergencies and they must communicate vital information during critical phases of operations. Errors in communications, for example, a wrong treatment priority, will compromise safe and effective patient care. Dispatchers' failures may lead to a delay in care and may contribute to the patient's death [7]. Therefore, although the dispatchers are not at the forefront of the "hands on" rescue, they bear high work-related responsibility.

Dispatchers often use specific instruction protocols or computerized call-taking systems which can increase the sensitivity for detecting cardiac arrest, as an example, to $77 \%$ and the specificity to $99 \%$ [8]. In dispatcherdirected cardiopulmonary resuscitation (CPR), the same dispatcher who receives the emergency call not only coordinates the dispatch of professional rescuers (e.g. fire and/or police and emergency medical services), but is 
also trained to remain on the telephone and verbally assist bystanders with the initiation of early CPR. The dispatcherassisted telephone CPR instructions are proven to increase survival rates as the chances of survival from cardiac arrest depend on early diagnosis and prompt initiation of CPR including defibrillation. A recent study revealed a threemonth survival rate of $5 \%$ when a cardiac arrest was not recognized by the dispatchers as compared to $14 \%$ when it was recognized $(p=0.04)$ [9]. Dispatchers' failure to identify a cardiac arrest was largely caused by deviation from their instruction protocol [10].

The high proportion of technical components and the need for rapid information processing are special work demands placed on dispatchers in fire departments. In total, the mental stress and strain experienced by dispatchers in emergency centres and its impact on their personal health have not been investigated so far.

The aim of this study was to assess the psychomental stress and strain among dispatchers in fire departments, particularly during emergency instructions by phone, and to evaluate their work ability.

Based on the literature, it is assumed that dispatchers experience a higher stress level (compared to the reference group) - especially due to their emergency instructions by phone call. As described in several studies, a relevant high stress level can lead to an elevation in biometric stress parameters (such as heart rate or clinical laboratory indices) and may increase the risk for work disability [11-13]. According to a review on work-related stressors and strain, it was concluded that both subjective aspects and objective indices (from physical examinations) are required to assess the level of strain and to promote mental health [14].

\section{Methods}

\section{Participants}

In the present cross-sectional study, the employees from a control centre of a metropolitan fire department were examined in the time period from October 2009 to April 2010. They were responsible for 1.8 million inhabitants.

The study cohort comprised all dispatchers from this fire department who worked full time in rotating shifts. They were former fire fighters who performed an additional training to coordinate and provide appropriate phone instructions for first aid. The dispatchers worked in a mixed emergency and fire system; that means, after dialing 112, the Europe-wide emergency phone number, the public can reach the different emergency services (ambulances, fire and rescue service and the police). In 2002, on average 540 deployments per day were recorded in this fire department and increased to more than 700 per day six years later.

A total of 27 male dispatchers were included in the study and represented $100 \%$ of all available dispatchers in this control centre. 20 of 22 available persons (91\%) who work at the same fire department agreed to serve as an internal control group. These fire fighters are performing administrative and coordinating tasks e.g. planning fire protection concepts for public buildings or rescue scenarios for major events. Others are responsible for the controlling of human and financial resources. As these controls just like dispatchers mainly perform tasks as office workers by using a computer and a telephone and doing this also without high physical activity (mainly in a sitting position), they appear as a suitable reference group.

All study participants were informed about the content and procedure of the study, the pseudonymized data analysis and the possibility of withdrawing from the study at any time. Prior to the examination all employees gave their written informed consent for participation in this voluntary study. None of the office participants withdrew their participation during the study period. The ethical review board of the Institute for Occupational and Maritime Medicine approved this study.

\section{General questionnaire Medical history}

A detailed general and workplace-specific medical history was taken and one clinically experienced physician examined thoroughly each employee to rule out that diseases could affect the results.

\section{Phase protocol}

In several studies, the most demanding fire fighting and rescue tasks of emergency workers in fire departments were explored by means of questionnaires [15]. According to these studies, experiences such as hearing that children are in burning buildings, carrying out victims, fire suppression, resuscitation, catastrophic injury to self or co-workers were classified as heavy psycho-mental load $[6,16]$.

All participants kept a log of events, non-events and breaks in phase protocols during each shift. Among dispatchers, an event was defined as an incoming emergency call characterized by

- Tasks that were objectively or subjectively perceived as psychologically stressful (in line with the above mentioned statements about most demanding rescue tasks), and/or

- Callers who were more difficult (because of language problems, aggression or hysteria).

In administrative workers, events were all situations that they perceived as stressful (e.g. conflicts with colleagues, problems with customers). 


\section{Instruments}

The instruments we used to evaluate the theoretical construct of the study are listed in Table 1.

\section{Mental/ physical strain Physical strain}

The participants' heart rate was continuously monitored and recorded by the portable telemetric beat-to-beat recorder Polar RS 800 with $1000 \mathrm{~Hz}$ sampling rate (Polar Electro, Oy-Kempele, Finland). This device was validated for the accurate measurement of NN intervals and for the purpose of the analysis of HRV [17]. As parameters of physical strain, the heart rate variability (HRV), the standard deviation of all $\mathrm{NN}$ intervals (SDNN) and the ratio of low- to high frequency power (LF/HF) were calculated. The NN intervals were visually inspected for artefacts. Occasional ectopic beats were identified and replaced with interpolated $\mathrm{NN}$ interval values (less than $1 \%$ of the data). HRV analyses were performed with Kubios HRV Version 2.

To assess the participants' energy expenditure, the SenseWear $^{\text {Ti }}$ Armband (SWA) (BodyMedia, Inc. Pittsburgh, Pennsylvania) was used $[18,19]$. This is a physical activity and lifestyle monitor that objectively measures free-living energy balance $[20,21]$. The armband worn on the right upper arm utilized a 2-axis accelerometer, heat flux sensor, galvanic skin response sensor, skin temperature sensor and a near-body ambient temperature sensor to gather data about the activity and energy expenditure.

This device calculates energy expenditure, expressed as the metabolic equivalent of task (MET). This parameter reflects the energy cost of physical activities and is defined as the ratio of metabolic rate during a specific physical activity to a reference metabolic rate. 1 MET is considered as the resting metabolic rate obtained during quiet sitting. MET values of activities range from 0.9 (sleeping) to 18 (marathons).

Both the heart rate monitor and armband were attached to the participants and were worn during the entire examined work shift. The devices are comfortable to wear. The continuously measured physical parameters were analyzed separately for the different phases during the examined shift.

Table 1 Instruments used to evaluate the theoretical construct of the study

\begin{tabular}{ll}
\hline Construct & Instruments \\
\hline Mental/physical strain & Heart rate, SDNN, LF/HF ratio \\
& Energy expenditure \\
& Clinical laboratory parameters \\
Work ability & WAI \\
\hline
\end{tabular}

\section{Clinical laboratory parameters}

For cortisol analysis all participants gave 5 salivary samples during the shift (due to the different shift lengths the sampling times were different -for the dispatchers 06:30, $09: 15,12: 00,14: 45$ and 17:30 and for the control group 08:00, 10:00, 12:00, 14:00 and 16:00). The samples were frozen after the end of each shift and stored at $-20^{\circ} \mathrm{C}$. The analysis was performed in a commercial laboratory using competitive enzyme immunoassay (ELISA).

Furthermore, urine samples were collected to determine adrenaline and noradrenaline levels, separately for the first and second part of the examined shift (dispatchers: from $06: 30$ to $11: 59$ and from 12:00 to 17:30; control group: from $07: 30$ to $11: 59$ and from 12:00 to 16:30).

After the shift, a blood sample was taken from all 27 dispatchers and from all 20 control subjects for the measurement of lymphocytes. The analysis was performed by flow cytometer (Becton Dickinson FACScalibur) in a commercial laboratory.

\section{Work ability \\ Work ability index (WAI)}

This standardized questionnaire reflects the ability to work based on the workers' self-perception. The WAI has also been validated in large international studies. It has a Cronbach's alpha between 0.72 and 0.80 [22]. The work ability index has strong predictive power with regard to the future course of work ability [23]. The higher the WAI scale (from 7 to 49), the better is the respondent's work ability; a good ability is assumed at a scale-score above 37. The WAI was repeatedly applied in research projects dealing with workplace health promotion in occupational health care.

\section{Statistical analysis}

Data was analyzed using SPSS for Windows (version 20.0 SPSS GmbH Software, Munich, Germany). Continuous variables were expressed as median (from min to max). The Mann Whitney test was performed for the comparison of unpaired groups. After adjustment for age and working hours per week, the linear regression analysis was applied for the metric values. All indicated p-values were two-sided, and an $\alpha$-value of $<0.05$ was regarded as statistically significant.

\section{Results}

\section{General questionnaire}

On average, the control group was slightly older than the dispatchers. There were no significant differences in all examined demographic data between the study groups. In addition, measurements of BMI and blood pressure revealed similar averages. The demographic, 
biometric and occupational data of both groups are listed in Table 2.

Based on the physical findings or underlying diseases no participant was excluded from the study. Cardiovascular diseases were present in $4(14.8 \%)$ of the dispatchers and in 7 (35.0\%) subjects from the control group. During the physical examination a hypertensive blood pressure was found in $1(3.7 \%)$ dispatcher and in $2(10.0 \%)$ control subjects. 12 (44.4\%) dispatchers and 8 (40.0\%) controls were suffering from diseases of the muscular-skeletal system. 5 dispatchers ( 2 controls) stated that they had diseases of the airways.

According to the general questionnaire, employment in the fire department was longer among control subjects than among dispatchers. However, on average, the dispatchers worked longer in their current position than the subjects from the control group (Table 2).

The occurrence of work disability within the last 12 months before the investigation was significantly $(\mathrm{p}=0.004)$ higher among dispatchers. No difference was found in the number of disability days (Table 2). Considering the last quarter, $58 \%$ of dispatchers and $42 \%$ of control subjects reported a work disability in the past 3 months before the study.

\section{Heart rate measurement}

The stated medicines taken by the participants did not affect the measured physiological parameters. The realtime heart rate was measured during the complete investigated shift and separately analysed for the three phases "event", "non-event" and "breaks". The average heart rate and heart rate variability of the dispatchers and the control group in the different phases and the duration of the phases in the examined shift are shown in Table 3.
According to the phase protocol, the dispatchers had longer working days and longer breaks than the control group. The duration of stressful events due to phone calls in dispatchers or due to demanding situations in the control group was similar in spite of a significantly higher number of events in dispatchers (Table 3).

Although dispatchers showed no significant differences in heart rate between the different phases, in comparison to the control group they had significantly higher heart rates in all phases and a tendency of decreased heart rate variability in event and non-event phases. In addition, the LF/HF ratio reflecting the global sympatho-vagal balance was high, especially in dispatchers, but also in the control group, indicating a pronounced sympathetic response.

\section{Energy expenditure}

Energy costs of the dispatchers were assessed by means of the SenseWear armband. The mean metabolic equivalent of task (MET) of all participants during the shift was 1.39 (SD 0.43) without noticeable differences between dispatchers and control group.

\section{Determination of salivary cortisol}

On average, the course of the measured values corresponds to the expected circadian rhythm of cortisol with a peak value at 6:00 to 7:00. The values of the control group matched those of the dispatchers in the corresponding measurement period, with a slightly lower value at 14:00 (Figure 1). The mean values showed no significant differences between the study groups. Looking at the individual measurements, outliers from the normal course could be seen. In $50 \%$ of the cases, these

Table 2 Demographic, biometric and occupational data of the control group and the dispatchers

\begin{tabular}{lll}
\hline & $\begin{array}{l}\text { Control group } \\
(\mathbf{n = 2 0})\end{array}$ & $\begin{array}{l}\text { Dispatchers } \\
\text { (n= 27) }\end{array}$ \\
\hline $\begin{array}{l}\text { Demographic and biometric data } \\
\text { Age, years (median (min.-max.)) }\end{array}$ & $46(31-57)$ & $39(34-51)$ \\
Living in partnership, \% & $72.2 \%$ & $84.0 \%$ \\
Presence of children, \% & $68.4 \%$ & $84.0 \%$ \\
Current smoker, \% & $21.1 \%$ & $12.0 \%$ \\
Body mass index (median (min.-max.)) & $27.7(22.1-37.0)$ & $27.5(22.7-40.1)$ \\
Blood pressure, mmHg (median (min.-max.)) & $130(110-170) / 80(70-90)$ & $130(100-160) / 80(60-110)$ \\
Occupational data (median (min.-max.)) & & $16.5(9-30)$ \\
Employment at the fire department, years & $23.0(2.5-32)$ & $2.5(0.5-17)$ \\
Employment in the current position, years & $1.0(0.5-5.0)$ & $46(34-79)$ \\
Average working hours per week, hours & $447,5(20-61)$ & $84.0 \%$ \\
Work disability ${ }^{2}$ yes/no (\% yes) & $42.1 \%$ & $14(0-85)$ \\
Work disability ${ }^{\text {, }}$ number of days (median (min.-max.)) & $14(0-90)$ & \\
\hline
\end{tabular}

${ }^{\mathrm{a}}$ During the past year. 
Table 3 Average heart rate (variability) and duration of the phases during the examined shift of the control group and the dispatchers

Control group $(n=20) \quad$ Dispatchers $(n=27) \quad p^{a}$

Control group vs. dispatchers

Event phases ${ }^{\text {b }}$ (median (min.-max.))

\begin{tabular}{|c|c|c|c|}
\hline Cumulative duration, min & $0(0-60)$ & $4.0(0-47)$ & 0.901 \\
\hline Number of events & $0(0-3)$ & $0(0-5)$ & 0.006 \\
\hline beats/min & $64.1(57.5-69.8)$ & $76.6(72.2-87.4)$ & 0.001 \\
\hline SDNN, ms & $105.1(58.8-159.7)$ & $70.4(40.4-152.9)$ & 0.052 \\
\hline LF/HF & $4.5(1.3-14.9)$ & $5.5(0.4-30.1)$ & 0.281 \\
\hline \multicolumn{4}{|c|}{ Non-event phases ${ }^{c},($ median (min.-max.)) } \\
\hline Cumulative duration, hours & $6.7(5.8-8.2)$ & $9.1(7.8-9.6)$ & 0.001 \\
\hline beats/min & $69.2(59.9-79.3)$ & $74.6(56.4-89.8)$ & 0.034 \\
\hline SDNN, ms & $128.3(59.2-357.6)$ & $83.6(65.1-158.6)$ & 0.034 \\
\hline $\mathrm{LF} / \mathrm{HF}$ & $5.1(2.6-14.2)$ & $6.5(1.2-11-0)$ & 0.629 \\
\hline \multicolumn{4}{|c|}{ Breaks $^{\mathrm{d}}$, (median (min.-max.)) } \\
\hline Cumulative duration, hours & $0.5(0-0.7)$ & $1.5(0.5-1.8)$ & 0.001 \\
\hline beats/min & $69.3(64.0-82.3)$ & $77.3(60.3-89.3)$ & 0.036 \\
\hline SDNN, ms & $112.8(56.1-155.9)$ & $91.6(53.8-267.0)$ & 0.527 \\
\hline LF/HF & $4.7(1.8-9.8)$ & $6.7(1.7-30.1)$ & 0.239 \\
\hline
\end{tabular}

peaks correlated with phone calls marked as psychologically stressful in the phase protocol.

\section{Determination of catecholamine in 24-hour urine}

The adrenaline levels of the dispatchers (Table 4) were slightly lower than those of the control group (n.s.).
Noradrenaline levels showed smaller differences between the groups.

\section{Lymphocytes}

There was no significant difference between dispatchers and the control group regarding the different subtypes

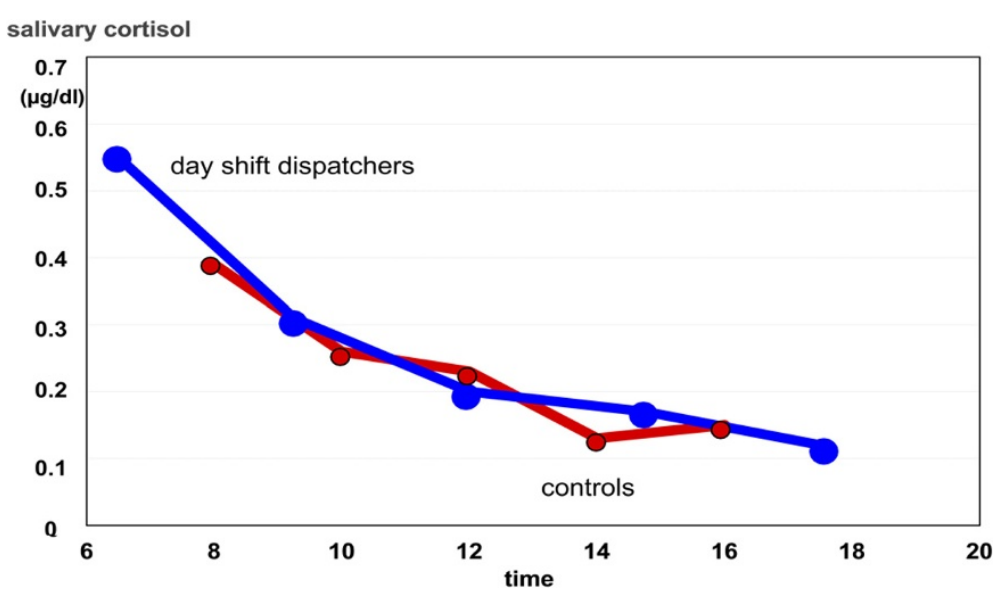

Figure 1 Salivary cortisol of dispatchers and controls. 
Table 4 Laboratory parameters of the control group and the dispatchers

\begin{tabular}{|c|c|c|c|c|}
\hline & $\begin{array}{l}\text { Control group } \\
(n=20)\end{array}$ & $\begin{array}{l}\text { Dispatchers } \\
(\mathrm{n}=27)\end{array}$ & Reference values & $\begin{array}{l}P^{a} \\
\text { Control group vs. dispatchers }\end{array}$ \\
\hline \multicolumn{5}{|c|}{$\begin{array}{l}\text { Urine catecholamines separated for first and second half } \\
\text { of the shift [ } \mathrm{\mu g} / \mathrm{g} \text { creatinine] (median (min.-max.)) }\end{array}$} \\
\hline Noradrenaline $1^{\text {st }}$ half & $27.8(9.6-53.9)$ & $30.5(22.2-51.1)$ & n.a. & 0.313 \\
\hline Noradrenaline $2^{\text {nd }}$ half & $32(8.7-58.5)$ & $23.3(15.9-42)$ & n.a. & 0.098 \\
\hline Adrenaline $1^{\text {st }}$ half & $7.4(2.8-29.3)$ & $6.45(2.8-27.1)$ & n.a. & 0.145 \\
\hline Adrenaline $2^{\text {nd }}$ half & $7.8(3.2-16.9)$ & $5.3(2.1-17.5)$ & n.a. & 0.144 \\
\hline \multicolumn{5}{|c|}{ Serum lymphocytes at the end of the shift (median (min.-max.)) } \\
\hline Lymphocytes (\% of Leucocytes) & $31.1(15.8-46.9)$ & $29.2(19.3-55.9)$ & $25-45$ & 0.568 \\
\hline \% T-Helper Lymphocytes (CD4+) & $46.5(24-58)$ & $44(31-70)$ & $30-62$ & 0.404 \\
\hline \% NK-Cells (CD3-, CD16/56+) & $16(7-22)$ & $13(8-25)$ & $5-29$ & 0.237 \\
\hline \% B-Lymphocytes (CD19+) & $11.5(6-22)$ & $14(5-20)$ & $7-23$ & 0.226 \\
\hline
\end{tabular}

of lymphocytes in blood samples. The same applies to the percentage of natural killer cells between the groups (Table 4).

\section{Work ability index (WAI)}

After adjustment for age and working hours per week, the dispatchers had a significantly lower work ability index than the control group $(36.2 \pm 6.4$ and $40.1 \pm 5.3$ respectively; $\mathrm{p}=0.009$ ). More than $84 \%$ of the control group and only $45 \%$ of the dispatchers were classified as good or excellent according to the WAI work ability groups. Table 5 demonstrates the distribution of the WAI within the group of dispatchers and the control group.

\section{Discussion}

In this study, the average heart rate, its variability and laboratory parameters were measured as strain responses to job challenges. The fact that in all examined phases the average heart rate of the dispatchers was in the normal range may indicate that they had adapted to their job-related stress. During event phases, however, the average heart rates of the dispatchers and the control group were 78 and 65 beats $/ \mathrm{min}(\mathrm{p}=0.001)$. As the dispatchers were not noticeably physically stressed (according

Table 5 Distribution into the work ability index (WAI) categories of the control group and the dispatchers

\begin{tabular}{lll}
$\begin{array}{l}\text { WAI scale for } \\
\text { work ability }\end{array}$ & $\begin{array}{l}\text { Control group } \\
(\mathbf{n = 2 0})\end{array}$ & $\begin{array}{l}\text { Dispatchers } \\
(\mathbf{n = 2 7 )}\end{array}$ \\
\hline Poor (7-27) & $5.3 \%$ & $8.3 \%$ \\
Moderate (28-36) & $10.5 \%$ & $45.8 \%$ \\
Good (37-43) & $52.6 \%$ & $33.3 \%$ \\
Excellent (44-49) & $31.6 \%$ & $12.5 \%$ \\
\hline
\end{tabular}

to the armband monitor their MET was 1.41 on average), the significant differences in heart rate are assumed to be caused mainly by their chronic job-related mental stress. The increased heart rate among dispatchers compared to controls - although being in normal ranges - can indicate a preliminary stage of a health disorder and probably a higher risk for work disability [13].

Correspondingly, the heart rate variability was reduced particularly during the event phases, which also suggests chronic stress effects. In contrast, between the different phases no significant differences of heart rate, heart rate variability and laboratory findings (salivary cortisol, catecholamines in urine or lymphocytes in serum) were observed. Thus, during the examined shift only chronic stress effects (e.g. elevated heart rate at the beginning and during the shift) could be measured, but no acute responses.

In a recent study, fire fighters were examined, first under a single condition during exercise on a cycle ergometer and second during the same exercise combined with a computerized fire fighting strategical and tactical decision-making challenge [24]. Since the fire fighters' heart rates and their serum catecholamines were significantly higher during the second condition, the authors concluded that particularly the addition of a mental challenge to physical stress alters responses to stress during fire fighting. These findings highlight the significance of mental stress due to decision-making in emergencies. This kind of stress (coordination of imaginary emergency tasks) reflects the typical job-demands of dispatchers to a high degree, also in contrast to the job demands of the examined control group working in the office. Among call centre workers as office workers who also don't experience this mental stress due to decisionmaking (similar to the present control group) a higher work-related stress was described as a risk factor for 
psychological health, and especially for a lower selfassessed work ability (WAI) [25].

Although they are not subjected to high physical exertion as shown in the present study - the mental stress caused by the coordination of rescue tasks during emergency calls under these specific conditions is obviously very high for dispatchers. In addition, after emergencies, fire fighters have the opportunity to exchange their emotions regarding the mutually experienced rescue actions as a team process when they return to their fire department. Dispatchers, however, often have to manage different emergencies in quick succession without having an opportunity to cope with their emotions and speak with others about their feelings. Compared to the internal controls, a higher frequency of shortterm events was confirmed in this study.

Furthermore, this study revealed significantly lower WAI among dispatchers than in the examined control group. In line with this self-assessment, a significantly higher frequency of disabilities had occurred objectively in dispatchers during the past year. In both study groups we found an equal number of disability days (on average 22 days per year) in the past year, but the dispatchers reported more acute, short-term disabilities (as a possible early sign of burnout) and less often chronic diseases (correspondingly, the control group distinctly more often stated cardiovascular diseases). The level of disability is extraordinarily high compared to the German general working population (12.8 disability days per year) [26].

It is plausible that the observed impaired work ability of dispatchers in comparison to the control group might be due to their high mental stress at the worksite [27]. This kind of stress can lead to a decreased well-being and consequently to a higher number of disability days [11] - also without a corresponding elevation of objective stress parameters (such as heart frequency) [12,28]. Most of available studies on work ability using the WAI haven't included biometric measurements [13]. Sometimes contradicting findings were described concerning work ability and objective variables $[28,29]$. In line with the present results, some studies revealed that disabled employees didn't demonstrate increased biometric stress parameters [11]. Parkka et al. [11] found only modest, but significant correlations between self-assessed stress level and physiological variables (such as heart rate or activity) among people participating in a work ability rehabilitation program. Furthermore, the authors described conflicting correlations at individual level. Therefore, psychological instruments, such as WAI, appear to be more sensitive to determine work ability than biometric parameters [12].

As a limitation of this study, the number of examined participants was low so that some possible relations between job-related stressors and outcome variables may not be clearly shown. However, in spite of the small number, some significant differences became evident, e.g. the strong relationship between the investigated occupational group and self-assessed work ability. A further limitation of this study is a selection bias which could have influenced the study results: it can't be excluded that some individuals with working ability restrictions were employed in the rescue coordination centre due to transfers from other fire fighting services. It is also possible that voluntarily recruited dispatchers had already accumulated work-related health complaints and had a higher tendency towards health problems. Moreover, as all study participants were only examined once, it is unclear to what degree the stress load varies from day to day. To reduce this shortcoming the participants were examined randomly on different weekdays in a 7-month time period.

We recommend the development or establishment of more precise dispatch protocols and specified training programs for dispatchers in the communities to improve their performance. The implementation of such standardized protocols for the assessment of the patient's health status is reported to increase the detection of health impairments by emergency medical dispatchers and thus to improve the treatment [30-32]. Furthermore, the dispatchers should have suitable opportunities for coping with their emotions and exchanging their feelings and impressions at regular intervals to reduce their observed chronic stress level.

Dispatchers' competence in CPR via phone is described as being dependent on re-training and a feedback on patient outcome [33]. Avoiding vague language, giving specific instructions for checking a patient, and finally reminding the caller to perform the explained procedures led to a high rate of successful communications. In addition, Dowdall-Thomae et al. (2009) presented a Peer Support Action Plan for several different intervention techniques as a coaching and support strategy in order to correct behaviours and keep the rescue workers at their optimum level of functioning and performance (problem-focused and seeking social support) [34]. Other authors also confirmed that (emotional) social support is a crucial measure to cope with job-related stress in emergency personnel [35-37].

Furthermore, video communication through mobile phones nowadays principally available in many situations can improve communication and avoid misunderstanding. This may provide a new basis for dispatcher assistance and can contribute to improved rescuer compliance [38].

\section{Conclusions}

The dispatchers' participating in this study had an elevated heart rate and reduced heart rate variability at the beginning and during the examined shift compared to the control group, probably indicating a higher level of 
chronic work-related stress. Additionally, they showed a significantly increased risk of work disability compared to the control group. Further studies are required to explore dispatchers' stress load and to draw conclusions concerning the effectiveness of appropriate intervention measures.

\section{Abbreviations}

CPR: Cardiopulmonary resuscitation; HRV: Heart rate and its variability; LF/HF: Ratio of low-high frequency power; MET: Metabolic equivalent of task: NN interval: Heartbeat-to-heartbeat interval; SD: Standard deviation; SDNN: Standard deviation of all NN intervals; SWA: SenseWear ${ }^{\mathrm{TM}}$ Armband; WAl: Work ability index.

\section{Competing interests}

Our work has been funded by a grant of the Hamburg fire department. The grant has been given to the Institute for Occupational and Maritime Medicine, ZfAM, University Medical Centre Hamburg-Eppendorf. No author has personally received any funding. Representatives of the fire department or any other external institution have neither influenced the measurements, the data collection and analysis nor the preparation of the manuscript. The authors declare that they have no conflict of interest.

\section{Authors' contributions}

All authors had full access to all data. XB and RW had the original idea for the paper and vouch for the integrity of the analysis. MO and DW performed medical examinations and took samples for laboratory analysis at the worksite. MO, BP, RW and DW analysed the data. MO and DW wrote and edited the manuscript. All authors collaborated in interpreting the data and have read and approved the final manuscript.

\section{Acknowledgements}

The authors thank all participants of the Hamburg fire department for participation in this study. Furthermore, we express our gratitude to Robina Mick and Hanna Graef for their support on the spot. We also thank Dr. Alexander Jaroslaw Galach for his technical support.

\section{Author details}

${ }^{1}$ Institute for Occupational and Maritime Medicine, Hamburg State Department for Health and Consumer Protection, ZfAM, University Medical Center Hamburg-Eppendorf, Seewartenstrasse10, D-20459 Hamburg, Germany. 'Department of Pulmonary Medicine, Asklepios Hospital Harburg, Hamburg, Germany. Institute for Occupational Medicine, Charité University Medicine Berlin and EOM Society, Berlin, Germany.

Received: 27 December 2013 Accepted: 11 September 2014 Published online: 30 September 2014

\section{References}

1. al Naser F, Everly GS Jr, Ibrahim, al Khulaifi Ml: Overcoming the effects of disasters: a rationale for the Kuwaiti CISM Program. Int J EmergMent Health 2001, 3:11-13.

2. Berger W, Coutinho ES, Figueira I, Marques-Portella C, Luz MP, Neylan TC, Marmar CR, Mendlowicz MV: Rescuers at risk: a systematic review and meta-regression analysis of the worldwide current prevalence and correlates of PTSD in rescue workers. Soc Psychiatry PsychiatrEpidemiol 2012, 47:1001-1011.

3. al-Naser F, Everly GS Jr: Prevalence of posttraumatic stress disorder among Kuwaiti firefighters. Int J EmergMent Health 1999, 1:99-101.

4. Fent KW, Evans DE: Assessing the risk to firefighters from chemical vapors and gases during vehicle fire suppression. J Environ Monit 2011, 13:536-543.

5. De Vos AJ, Cook A, Devine B, Thompson PJ, Weinstein P: Effect of protective filters on fire fighter respiratory health during simulated bushfire smoke exposure. Am J Ind Med 2006, 49:740-750.

6. Boxer PA, Wild D: Psychological distress and alcohol use among fire fighters. Scand J Work Environ Health 1993, 19:121-125.

7. Greenwood MJ, Heninger JR: Structured communication for patient safety in emergency medical services: a legal case report. PrehospEmerg Care 2010, 14:345-348.
8. Flynn J, Archer F, Morgans A: Sensitivity and specificity of the medical priority dispatch system in detecting cardiac arrest emergency calls in Melbourne. Prehosp Disaster Med 2006, 21:72-76.

9. Berdowski J, Beekhuis F, Zwinderman AH, Tijssen JG, Koster RW: Importance of the first link: description and recognition of an out-of-hospital cardiac arrest in an emergency call. Circulation 2009, 119:2096-2102

10. Hallstrom AP, Cobb LA, Johnson E, Copass MK: Dispatcher assisted CPR: implementation and potential benefit. A 12-year study. Resuscitation 2003, 57:123-129.

11. Parkka J, Merilahti J, Mattila EM, Malm E, Antila K, Tuomisto MT, Saarinen AV, van Gils M, Korhonen I: Relationship of psychological and physiological variables in long-term self-monitored data during work ability rehabilitation program. IEEE Trans InfTechnol Biomed 2009, 13:141-151.

12. Gupta N, Jensen BS, Sogaard K, Carneiro IG, Christiansen CS, Hanisch C, Holtermann A: Face validity of the single work ability item: comparison with objectively measured heart rate reserve over several days. Int J Environ Res Public Health 2014, 11:5333-5348.

13. Lindholm H, Sinisalo J, Ahlberg J, Hirvonen A, Hublin C, Partinen M, Savolainen A: Attenuation of vagal recovery during sleep and reduction of cortisol/ melatonin ratio in late afternoon associate with prolonged daytime sleepiness among media workers with irregular shift work. Am J Ind Med 2012, 55:643-649.

14. Ezoe S, Morimoto K: Quantitative assessment of stressors and stress reaction: a review. Sangyo lgaku 1994, 36:397-405.

15. Bugajska J, Zuzewicz K, Szmauz-Dybko M, Konarska M: Cardiovascular stress, energy expenditure and subjective perceived ratings of fire fighters during typical fire suppression and rescue tasks. Int J OccupSaf Ergon 2007, 13:323-331.

16. Beaton R, Murphy S, Johnson C, Pike K, Corneil W: Exposure to duty-related incident stressors in urban firefighters and paramedics. J Trauma Stress 1998, 11:821-828.

17. Cassirame J, Tordi N, Mourot L, Rakobowchuk M, Regnard J: Using of new beat to beat recorder system for traditional analysis of heart rate variability. Sci Sport 2007, 22:238-242.

18. Miwa H, Sasahara S, Matsui T: Roll-over detection and sleep quality measurement using a wearable sensor. Conf Proc IEEE Eng Med BiolSoC 2007, 2007:1507-1510.

19. Al Otair H, Al-Shamiri M, Bahobail M, Sharif MM, BaHammam AS: Assessment of sleep patterns, energy expenditure and circadian rhythms of skin temperature in patients with acute coronary syndrome. Med SciMonit 2011, 17:CR397-CR403.

20. Shuger SL, Barry WW, Sui X, McClain A, Hand GA, Wilcox S, Meriwether RA, Hardin JW, Blair SN: Electronic feedback in a diet- and physical activitybased lifestyle intervention for weight loss: a randomized controlled trial. Int J BehavNutr Phys Act 2011, 8:41.

21. Sunseri M, Liden CB, Farringdon J, Pelletier R, Safier S, Stivoric J, Teller A, Vishnubhatla S: The SenseWear armband as a Sleep Detection Device. 2012. http://sensewearbodymediacom/SenseWear-Studies/SW-Whitepapers/TheSenseWear-armband-as-a-Sleep-Detection-Device Accessed at May 2012.

22. Tuomi $K$, Huuhtanen $P$, Nykyri $E$, Ilmarinen J: Promotion of work ability, the quality of work and retirement. Occup Med (Lond) 2001, 51:318-324.

23. Hasselhorn H, Freude G: Der Work Ability Index-ein Leitfaden. Dortmund Berlin, Dresden: Schriftenreihe der Bundesanstalt für Arbeitsschutz und Arbeitsmedizin: Sonderschrift; 2007:87.

24. Huang CJ, Webb HE, Garten RS, Kamimori GH, Evans RK, Acevedo EO: Stress hormones and immunological responses to a dual challenge in professional firefighters. Int J Psychophysiol 2010, 75:312-318.

25. Conway PM, Campanini P, Punzi S, Fichera GP, Camerino D, Francioli L, Neri L, Costa G: Work stress, common mental disorders and work ability index among call center workers of an Italian company. EpidemiolPrev 2013, 37:17-28.

26. Bundesanstalt für Arbeitsschutz und Arbeitsmedizin: Volkswirtschaftliche Kosten durch Arbeitsunfähigkeit 2010. In Book Volkswirtschaftliche Kosten durch Arbeitsunfähigkeit 2010. Berlin: BAuA; 2012.

27. Hagglund KM, Helsing C, Sandmark H: Assistant nurses working in care of older people: associations with sustainable work ability. Scand J Caring Sci 2011, 25:325-332

28. Nygard CH, Eskelinen L, Suvanto S, Tuomi K, Ilmarinen J: Associations between functional capacity and work ability among elderly municipal employees. Scand J Work Environ Health 1991, 17(1):122-127. 
29. Kaewboonchoo O, Saleekul S, Usathaporn S: Factors related to work ability among Thai workers. Southeast Asian J Trop Med Public Health 2011, 42:225-230.

30. Roppolo LP, Westfall A, Pepe PE, Nobel LL, Cowan J, Kay JJ, Idris AH: Dispatcher assessments for agonal breathing improve detection of cardiac arrest. Resuscitation 2009, 80:769-772.

31. Buck BH, Starkman S, Eckstein M, Kidwell CS, Haines J, Huang R, Colby D, Saver JL: Dispatcher recognition of stroke using the national academy medical priority dispatch system. Stroke 2009, 40:2027-2030.

32. Tonje L, Elisabeth S, Lars W: Handling of drug-related emergencies: an evaluation of emergency medical dispatch. Eur J Emerg Med 2009, 16:37-42.

33. Bang A, Ortgren PO, Herlitz J, Wahrborg P: Dispatcher-assisted telephone CPR: a qualitative study exploring how dispatchers perceive their experiences. Resuscitation 2002, 53:135-151.

34. Dowdall-Thomae C, Culliney S, Piechura J: Peer support action plan: northwest fire and rescue. Int J EmergMent, Health 2009, 11:177-183.

35. Dudek B, Koniarek J: Social support as a modifier of response to stress: theoretical aspects and measurement. Med $\operatorname{Pr} 2003,54: 427-435$.

36. Farnsworth JK, Sewell KW: Fear of emotion as a moderator between PTSD and firefighter social interactions. J Trauma Stress 2011, 24:444-450.

37. Fullerton CS, McCarroll JE, Ursano RJ, Wright KM: Psychological responses of rescue workers: fire fighters and trauma. Am J Orthopsychiatry 1992, 62:371-378.

38. Johnsen E, Bolle SR: To see or not to see-better dispatcher-assisted CPR with video-calls? a qualitative study based on simulated trials. Resuscitation 2008, 78:320-326.

doi:10.1186/s12995-014-0031-8

Cite this article as: Oldenburg et al:: Job-related stress and work ability of dispatchers in a metropolitan fire department. Journal of Occupational Medicine and Toxicology 2014 9:31.

\section{Submit your next manuscript to BioMed Central and take full advantage of:}

- Convenient online submission

- Thorough peer review

- No space constraints or color figure charges

- Immediate publication on acceptance

- Inclusion in PubMed, CAS, Scopus and Google Scholar

- Research which is freely available for redistribution 